\title{
PReS-FINAL-2167: What is the potential of intra-articular corticosteroid injections to induce sustained remission in children with juvenile idiopathic arthritis?
}

\author{
S Lanni ${ }^{1 *}$, F Bovis ${ }^{1}$, C Papadopoulou ${ }^{1}$, M Kostik ${ }^{1}$, Ml Gonzalez-Fernandez ${ }^{1}$, M Bohm', JC Nieto-Gonzalez ${ }^{1}$, \\ M Bertamino', A Martini ${ }^{1,2}$, A Ravelli, ${ }^{1,2}$
}

From 20th Pediatric Rheumatology European Society (PReS) Congress

Ljubljana, Slovenia. 25-29 September 2013

\begin{abstract}
Introduction
Intra-articular corticosteroid injections (iacis) are widely used in the management of children with juvenile idiopathic arthritis (JIA). Although this therapeutic intervention is generally considered for the treatment of children with arthritis in a small number of joints, the strategy of injecting simultaneously multiple joints has been advocated in children with polyarthritis. However, the relative indications of single and multiple iacis in the management of JIA remains unclear and controversial. Furthermore, the capacity of iacis to induce sustained remission of synovitis in injected joints is still poorly documented.
\end{abstract}

\section{Objectives}

To describe our 10-year experience on the use of single and multiple iacis in the management of children with JIA.

\section{Methods}

The clinical charts of 542 JIA patients who received an IACI in 1,2 or $\geq 3$ joints between January 2002 and December 2011 and had a follow-up duration of at least 6 months after the procedure were reviewed. The corticosteroid preparation used was triamcinolone hexacetonide for large joints and methylprednisolone acetate for small or difficult to access joints. For each patient, the follow-up period after the IACI was censored when one of the following events occurred: 1) flare of synovitis in

${ }^{1}$ IRCCS Istituto Giannina Gaslini, Genova, Italy

Full list of author information is available at the end of the article injected joints; 2) flare of synovitis in injected and uninjected joints; 3) follow-up visit with continued remission of synovitis in injected joints, but recurrence of synovitis in uninjected joints; 4) last follow-up visit with continued remission of synovitis in both injected and uninjected joints. For the purposes of the analysis, events 1) and 2) were considered together and defined as "flare of synovitis in injected joints", whereas events 3 ) and 4) were considered together and defined as "remission of synovitis in injected joints".

\section{Results}

Two hundred and fifteen (39.7\%) patients were injected in 1 joint, 107 (19.7\%) were injected in 2 joints and 220 $(40.6 \%)$ were injected in $\geq 3$ joints. Following IACI therapy, $138(25,5 \%)$ patients were in remission at last follow-up visit, whereas 120 (22.1\%), 93 (17.2\%), and 191 (35.2\%) experienced a flare of synovitis, respectively, in uninjected joints, injected joints and either injected and uninjected joints. The cumulative probability of survival without synovitis flare for patients injected in 1,2 , or $\geq$ 3 joints was $69,46,49 \%$, respectively, at 1 year; 59, 31, $30 \%$, respectively, at 2 years; and 40,21, 19\%, respectively, at 3 years.

\section{Conclusion}

IACI therapy, either in single or multiple joints, was able to induce sustained remission of synovitis in a sizable number of patients. Our findings indicate that iacis remain a mainstay in the management of children with JIA, even in the current biologic era. 


\section{Disclosure of interest}

None declared.

\section{Authors' details}

${ }^{1}$ IRCCS Istituto Giannina Gaslini, Genova, Italy. ${ }^{2}$ University of Genova, Genova,

Italy.

Published: 5 December 2013

doi:10.1186/1546-0096-11-S2-P179

Cite this article as: Lanni et al:: PReS-FINAL-2167: What is the potential

of intra-articular corticosteroid injections to induce sustained remission

in children with juvenile idiopathic arthritis? Pediatric Rheumatology 2013

11(Suppl 2):P179.

Submit your next manuscript to BioMed Central and take full advantage of:

- Convenient online submission

- Thorough peer review

- No space constraints or color figure charges

- Immediate publication on acceptance

- Inclusion in PubMed, CAS, Scopus and Google Scholar

- Research which is freely available for redistribution

Submit your manuscript at www.biomedcentral.com/submit
C Biomed Central 